\title{
Association of PPARGC1A Gene Variants with Hypertension in Korean Population
}

\author{
Hyun-Seok Jin ${ }^{1, *}$ and Sangwook Park ${ }^{2, \dagger, *}$ \\ ${ }^{1}$ Department of Biomedical Laboratory Science, College of Life and Health Sciences, \\ Hoseo University, Asan 31499, Korea \\ ${ }^{2}$ Department of Biomedical Laboratory Science, College of Health and Medical Science, \\ Sangji University, Wonju 26339, Korea
}

\begin{abstract}
Hypertension (HTN) is one of the cardiovascular disease risk factors. Peroxisome proliferator-activated receptor $\gamma$ coactivator 1 alpha (PPARGC1A) is involved in a master modulator of mitochondrial biogenesis, and pulmonary arterial hypertension. In this study, we report results of PPARGC1A were associated with hypertension and its intermediate phenotype of systolic (SBP) and diastolic blood pressure (DBP) in the Korean population. In detail, identifying a susceptibility locus, 3 SNPs for HTN, 2 SNPs for SBP, 3 SNPs for DBP at $P<0.05$. Among them, rs1472095 in $P P A R G C 1 A$ gene statistically demonstrated one of the significant correlations with Hypertension $(P$-value $=0.00359,0 R=0.8,95 \%$ $\mathrm{CI}=0.68 \sim 0.93$ ). The minor allele (T) of $P P A R G C 1 A$ was statistically associated with the increased value of DBP, SBP, and the increase risk of hypertension. We aim to manifest a significant association between genetic variant in $P P A R G C 1 A$ and hypertension. This finding suggested that association of PPARGC1A genetic polymorphism and HTN accelerates our understanding of blood pressure control and underlines potential drug targets for treatment of hypertension.
\end{abstract}

Key Words: DBP, Hypertension, PPARGC1A, SBP

\section{서 론}

전세계적으로 심혈관 질병의 주요 원인인 고혈압은 해 결해야 할 대표적인 세계 공중보건 질병 중 하나이다(세 계보건기구, $\mathrm{WHO}, 2013)$. 적어도 9억 7천만 명의 세계인 들이 고혈압을 않고 있고 이 수치는 2021년까지 15억 이 상까지 증가할 것으로 추정하고 있다(Kearney et al., 2005). 실제로, 우리나라 건강보험심사평가원의 5년간 심사년도 별(2015 2019년) 고혈압 환자수의 추이를 보면 매년 20 30 만명이 꾸준히 상승하였다(Healthcare Bigdata, 2019). 고 혈압(hypertension)은 여러 가지 원인으로 혈압이 정상 범

Received: February 24, 2021 / Accepted: March 25, 2021

* Professor

${ }^{\dagger}$ Corresponding author: Sangwook Park. Department of Biomedical Laboratory Science, Sangji University, 83 Sangjidae-gil, Wonju, Gangwon-do 26339, Korea.

Tel: +82-33-738-7682, Fax: +82-33-738-7652, e-mail: spark367@sangji.ac.kr

(C) The Korean Society for Biomedical Laboratory Sciences. All rights reserved.

(c) This is an Open Access article distributed under the terms of the Creative Commons Attribution Non-Commercial License (http://creativecommons.org/licenses/by-nc/3.0/) which permits unrestricted non-commercial use, distribution, and reproduction in any medium, provided the original work is properly cited.
위(120/80 mmHg)보다 높아진 상태를 의미하는데, 이러한 고혈압 상태가 오랫동안 지속될 경우에는 심혈관 질환을 포함한 다양한 대사질환의 발생을 유발한다(Carretero and Oparil, 2000). 또한, 고혈압 발생에 대한 다양한 유전적 연 구를 통해 유전적 인자의 영향이 약 30 60\%에 해당하고 있음을 많은 연구들에 인해 밝혀졌다(Singh et al., 2016; Cabrera et al., 2019). 이에 고혈압에 대한 많은 전장유전 체 연관 연구를 통해 다양한 유전자들이 발표되었다(Pan et al., 2015; Warren et al., 2017; El Rouby et al., 2019). 그러나, 그렇게 발표된 유전자들 중에 다수는 한국인에서의 재현 성 여부가 미처 분석되지 않은 유전자들도 존재하기에 이러한 유전자들에 대한 한국인에서의 고혈압 상태 또는 
혈압 수치와의 연관성 분석을 통한 재현성 분석이 한국 인의 고혈압을 유전적 관점에서 이해하기 위해 필요하다.

Peroxisome proliferator-activated receptors (PPAR)은 핵호르 몬수용체 superfamily에 속하는 리간드 활성화 전사인자이 며 세포 내 에너지 물질 대사를 조절한다. 또한, 세포 에 너지 대사에 중요한 역할을 하는 자가포식-리소좀 기능 조절에도 역할이 밝혀졌다(Sinha et al., 2020). PPAR은 3개 의 isotype (PPAR $\alpha, \operatorname{PPAR} \beta / \delta$ PPAR $\gamma$ )로 구성된 전사인자로 써 지질, 탄수화물 대사 및 미토콘드리아 대사에 관여하 는 유전자를 조절하는 역할을 한다(Li et al., 2018; VargasSánchez et al, 2020). 특히, PPAR $\gamma$ 는 포도당 대사와 관련된 유전자들을 조절하는 지방세포 분화의 주요 조절자로 알 려져 있을 뿐만 아니라 근육형성과 산소흡수, 힘과 인내력 과 같은 스포츠 유전자와의 연관성에도 관여한다(Popov, 2018; Qiu, 2020). PPAR $\gamma$ coactivator $1 \alpha$ (PPARGC1A)는 $\mathrm{PGC}-1 \alpha$ 라고도 표기하며 PPAR $\gamma$ 과 결합하여 세포 내 다양 한 대사기능에 관여한다(Puigserver et al., 1998). 현재까지 10 개 이상의 isoform이 존재하며 혈관신생(Angiogenesis), 미토콘드리아 생합성(Mitochondrial biogenesis), 근육비대증 (Muscle hypertrophy), 포도당 신합성(Gluconeogenesis) 등에 영향을 준다(Martinez-Redondo et al., 2015). 한편, 폐고혈압 (pulmonary hypertension, $\mathrm{PH}$ )은 폐동맥 평활근 세포의 증식 과 혈관재형성을 증가시키는 대사변형이 특징이다(Yeligar et al., 2018). 미토콘드리아 유전자 발현 및 생합성을 조절 하는 PPARGC1A와 협력하는 PPAR $\gamma$ 는 낮은 $\mathrm{PH}$ 에서 폐 동맥 평활근 세포의 증식을 조절하기도 한다(Hart et al, 2018). 최근 10여년 동안 스포츠 유전체학(sports genomics) 을 주제로 한 과학논문들 중 PPAR 유전자와 공동활성체 (coactivator)에 대한 연구가 많이 이루어지고 있다(Ahmetov and Fedotovskaya, 2015; Petr et al., 2019).

본 연구는 전장유전체 분석을 이용하여 PPARGCIA 유 전자 영역에 위치한 $\mathrm{SNP}$ 들과 고혈압의 질병 상관성 분석 을 통해 한국인에서도 PPARGC1A 유전자 변이가 고혈 압 및 혈압과의 상관관계가 있다는 것을 확인하였다.

\section{재료 및 방법}

\section{연구 대상자}

한국인 유전체역학조사사업(Korean Genome and Epidemiology, KoGES)의 일부분으로써 한국인유전체분석자 료(Korean Association Resource, KARE)의 국내 연구 대상 자를 대상으로 본 연구를 수행하였다(Cho et al., 2009).
사용된 역학정보 및 유전정보는 질병관리청 인체자원은 행으로부터 분양을 받아 사용하였다(17100901-01-01). 본 정보는 질병관리청에서 2001년에 시작한 코호트 연구로 써 경기도 안성시와 안산시 주거인들을 대상으로 한국인 역학 및 유전체 연구를 수행하였다. 성인(40 69세) 남녀 10,038 명을 모집하였으며, 이들 중에서 정도관리(Quality Control, QC) 과정을 통해 유전체 분석 기준에 적합하지 않은 1,196 명이 제외되었으며 최종적으로 이용 가능한 연 구 대상자는 총 8,842명(남성: 4,183명, 여성: 4,659명)이 었다. 고혈압에 대한 유전변이와의 상관성 연구를 위해 8,842 명의 대상자를 대상으로 환자군(고혈압)과 대조군 을 선별하였다. 또한, 고혈압 치료 또는 혈압에 영향을 줄 수 있는 약물 치료를 받은 1,291명을 제외하였고 최종 7,551 명을 연구 대상자로 선별하여 정량적 연관성 분석을 수행하였다. 고혈압 치료를 받고 있는 환자 961 명을 고혈 압 환자군(1,968명)에 포함하여 로지스틱 회귀 분석을 수 행하였다. 따라서 전체 환자군은 총 1,968 명을 선정(수축 기 혈압 $140 \mathrm{mmHg}$ 이상 또는 이완기 혈압 $90 \mathrm{mmHg}$ 이 상)하였고 수축기 혈압이 $120 \mathrm{mmHg}$ 미만이면서 이완기 혈압이 $80 \mathrm{mmHg}$ 미만이면 건강 대조군 $(\mathrm{N}=4,452)$ 으로 선 별하였다. 환자군(고혈압)과 대조군(건강인)의 평균 연령 은 49.4 \pm 8.11 세와 $56.8 \pm 8.44$ 세로 유의한 통계적 차이를 나타냈다. 본 연구 결과는 호서대학교와 질병관리본부 $(\mathrm{KNIH})$ 로부터 연구윤리 승인을 얻은 후 유전정보 분석을 수행하였다(1041231-170822-BR-062-01).

\section{혈압 측정 방법}

병원의 숙련된 간호사의 도움으로 연구 대상자의 팔 둘 레를 적절한 커프를 이용하여(수은 혈압계, W. A. Baum, Copiague, NY, USA)로 혈압을 측정하였다. 대상자는 첫 혈압 측정 전에 5 분 동안 휴식을 취하게 하였다. 그리고 누운 자세를 유지한 채 5 분 이상의 시간차이를 두고 3 번 측정하였으며 그 평균값을 다음 유전 분석에 사용하였다.

\section{유전형 분석과 단일염기서열(Single Nucleotide Poly- morphism, SNP) 선별}

본 연구를 위해 유전형 KARE 자료를 바탕으로 단일염 기서열(SNP)을 선별하였다. 말초혈액으로부터 연구 대상 자의 DNA 시료를 분리 추출하였고, Genome-Wide Human SNP array 5.0 (Affymetrix, Inc., Santa Clara, CA, USA)를 사 용하여 유전형 판독을 하였다. 유전형 판독 정확도가 $98 \%$ 이하 또는 높은 missing genotype call rate (4\% 이상)을 나 
Table 1. Basic characteristics of the subjects in the KoGES

\begin{tabular}{lcccc}
\hline \hline \multirow{2}{*}{ Characterisitics } & \multirow{2}{*}{$\begin{array}{c}\text { Quantitative trait } \\
\text { analysis }\end{array}$} & \multicolumn{3}{c}{ Case-control analysis $^{* *}$} \\
\cline { 3 - 5 } & 7,551 & Normotensive & Hypertensive & $P$ value $^{* * *}$ \\
\hline Number of subjects & $3,747(49.6) /$ & $2,061(46.3) /$ & $910(46.2) /$ & 0.955 \\
Gender [men (\%)/women (\%)] & $3,804(50.4)$ & $2,389(53.7)$ & $1,058(53.8)$ & $<0.0001$ \\
Age $(M$ years $\pm \mathrm{SD})$ & $51.44 \pm 8.78$ & $49.39 \pm 8.11$ & $56.75 \pm 8.45$ & $<0.0001$ \\
Systolic blood pressure (SBP) $(M \mathrm{mmHg} \pm \mathrm{SD})$ & $115.65 \pm 17.25$ & $104.69 \pm 9.15$ & $139.42 \pm 17.27$ & $<0.0001$ \\
Diastolic blood pressure (DBP) $(M \mathrm{mmHg} \pm \mathrm{SD})$ & $74.21 \pm 11.27$ & $67.68 \pm 7.72$ & $88.97 \pm 10.90$ & $<0.0001$ \\
Total cholesterol $(M \mathrm{mg} / \mathrm{dL} \pm \mathrm{SD})$ & $190.68 \pm 35.71$ & $188.05 \pm 34.16$ & $197.37 \pm 37.70$ & $<0.0001$ \\
High density lipoprotein cholesterol $(M \mathrm{mg} / \mathrm{dL} \pm \mathrm{SD})$ & $44.85 \pm 10.03$ & $45.05 \pm 9.92$ & $43.73 \pm 10.26$ & $<0.26$ \\
Triglyceride $(M \mathrm{mg} / \mathrm{dL} \pm \mathrm{SD})$ & $159.97 \pm 105.54$ & $146.90 \pm 95.75$ & $190.22 \pm 115.38$ & $<0.0001$ \\
\hline
\end{tabular}

Abbreviations: M, mean value; SD, standard deviation. *Individuals who are not using hypertensive medications. **Controls (normotensive), $\mathrm{SBP}<120 \mathrm{mmHg}$ and DBP $<80 \mathrm{mmHg}$; Cases (hypertensive), SBP $\geq 140 \mathrm{mmHg}$ and/or DBP $\geq 90 \mathrm{mmHg}$ and/or antihypertensive medication. ${ }^{* *}$ Significantdifferences in characteristics between the normotensive and hypertensive subjects were determined by the twotailed Student's $t$-test

타낸 경우, $30 \%$ 초과의 heterozygosity를 가지거나, 성별 이 불분명한 대상자들은 제외되었다. 본 연구에서 분석한 $P P A R G C 1 A$ 전사체 양쪽 끝 말단에서 $\pm 5 \mathrm{~kb}$ 씩 확장한 범 위에 위치한 15 개의 $\mathrm{SNP}$ 들을 선택하였다. 선별된 $\mathrm{SNP}$ 들 의 염색체 위치는 UCSC Genome Browser (NCBI human $\mathrm{gb} 36,2006)$ 를 기준으로 하였다.

\section{통계 분석 및 상관성 분석}

통계 분석을 위해 PLINK version 1.07 (http://pngu.mgh. harvard.edu/ purcell/plink)과 SPSS (PASW Statistics v18.0, Chicago, IL, USA)을 사용하였다. 로지스틱 회귀 분석을 사용하여 고혈압 환자군과 건강 대조군에 대해 additive genetic model을 기반으로 한 유전적 변이의 상관성 분석 을 수행하였다. 수축기 혈압(SBP) 및 이완기 혈압(DBP)과 유전적 변이의 상관관계는 선형 회귀 분석을 사용하였다. 그리고 회귀 분석 전에 나이, 지역, 성별은 공변수로 처리 하여 분석하였다. 그리고 $P$ 값이 0.05 이하의 분석 값을 유의 수준의 기준으로 정하였다. 추가적으로, 특정 $\mathrm{SNP}$ 에 대한 대립 유전자 빈도의 지리적 분포를 확인하기 위해 서 Geography of Genetic Variants (GGV) browser (https:// popgen.uchicago.edu/ggv)를 이용하였으며 1000 Genome database를 기반으로 하였다(Marcus and Novembre, 2017).

\section{결 과 \\ $P P A R G C 1 A$ 유전자와 고혈압과의 로지스틱 회귀 분석}

연구 대상자들의 임상 표현형 특징을 Table 1에 나타냈 다. 고혈압 환자 $(\mathrm{N}=1968)$ 의 평균 나이, 평균 수축기 혈압

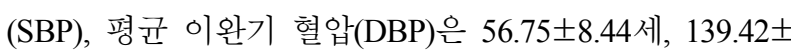
$17.27 \mathrm{mmHg}, 88.97 \pm 10.90 \mathrm{mmHg}$ 으로 나타났다(Table 1). 고혈압 환자군에서 모두 높은 수치를 나타냈고 Student $t$-검정을 통해 정상 혈압군과 고혈압 환자간에 $\mathrm{SBP}, \mathrm{DBP}$ 의 통계적 유의차이가 있었다(Table 1).

본 연구 대상인 PPARGCIA의 분석 대상 $\mathrm{SNP}$ 들은 $\mathrm{NCBI}$ human genome build 36 를 기준으로 하였고 4 번 염색체 상의 15 개 $\mathrm{SNP}$ 들이 분석 대상으로 선별되었다. 선별된 $P P A R G C 1 A$ 의 15 개 $\mathrm{SNP}$ 을 대상으로 고혈압 환자군과 건 강 대조군에 대한 로지스틱 회귀 분석에서도 연령, 성별, 지역은 공변수로 처리하였다. Additive genetic model을 유전 모델로 선택하였다. 그 결과 3 개 $\mathrm{SNP}$ 에서 통계적으로 유 의한 상관관계 $(P<0.05)$ 를 확인할 수 있었다(Table 2). 이 중 가장 높은 유의 수준 $(P=0.00359)$ 을 보여주는 $\mathrm{SNP}$ 은 rs1472095로 상대적 위험도는 0.80 (95\% 신뢰구간: 0.68 0.93)인 것으로 나타났다. rs472095의 minor allele는 T, major allele는 C인데, T염기를 보유할 경우에 고혈압 발병에 대 한 위험성이 낮은 경향으로 유의한 상관관계가 있는 것 을 알 수 있었다. Rs1472095은 SBP와 DBP에서도 통계적 유의성을 보여주고 있는데, minor allele를 가질 수록 점진 적으로 혈압 수치가 낮아지는 경향을 보이고 있다. 이러 
한 결과는 minor allele를 보유한 사람은 고혈압에 대한 상 대적 위험도가 낮아지는 환자-대조군 분석 결과와 일치 하는 것을 알 수 있다.

\section{$P P A R G C 1 A$ 유전자와 혈압과의 선형 회귀 분석}

15 개의 $\mathrm{SNP}$ 들을 대상으로 $\mathrm{SBP}$ 와 $\mathrm{DBP}$ 에 대해서도 상 관 분석을 시행하였다. 선형 회귀 분석을 하였으며 역시 연령, 성별 및 지역을 공변수로 처리하였다. 유전 모델은 additive genetic model을 기반으로 하였다. 그 결과 $\mathrm{SBP}$ 와 $\mathrm{DBP}$ 에서 공통적으로 2 개의 $\mathrm{SNP}$ 들이 통계적으로 유의한 상관관계를 보여주고 있었다(Table 2).

$\mathrm{SBP}$ 에서는 $\mathrm{rs} 1472095$ 가 가장 높은 유의 수준 $(\beta=-1.30$,
$P=0.00541)$ 을 보여 주었고, $\mathrm{DBP}$ 에서는 $\mathrm{rs} 2932966$ 에서 가 장 높은 유의 수준 $(\beta=-0.94, P=0.00298)$ 을 나타내었다. 이 들 SNP들은 minor allele를 가지게 될수록 보여주는 혈압 수치의 방향성 또한 $\mathrm{SBP}$ 와 DBP 모두에서 낮아지는 방향 으로 일치하고 있다.

\section{PPARGC1A 유전자의 유의한 SNP들에 대한 in silico 기능 분석}

고혈압에서 유의성을 보이는 $P P A R G C 1 A$ 의 $\mathrm{SNP}$ 들이 어떻게 유전자 혹은 단백질에 영향을 미칠 것인지를 HaploReg (https://pubs.broadinstitute.org/mammals/haploreg/ haploreg.php)에서 확인해 보았다. 확인 결과 고혈압 상태

Table 2. The association analysis results of SNPs in the PPARGC1A gene with blood pressure and hypertension in the Korean population

\begin{tabular}{|c|c|c|c|c|c|c|c|c|c|c|c|}
\hline \multirow[t]{2}{*}{ No. } & \multirow[t]{2}{*}{ SNP } & \multirow{2}{*}{$\begin{array}{l}\text { Minor } \\
\text { allele }\end{array}$} & \multicolumn{2}{|c|}{ MAF } & \multirow[t]{2}{*}{ Function } & \multicolumn{2}{|c|}{$\begin{array}{c}\text { Hypertension } \\
\text { (controls 4,450: cases 1,968) }\end{array}$} & \multicolumn{2}{|c|}{ SBP } & \multicolumn{2}{|c|}{ DBP } \\
\hline & & & Cases & Controls & & OR $(95 \% C I)$ & Add $P$ & beta \pm se & Add $P$ & beta \pm se & Add $P$ \\
\hline 1 & rs9790699 & $\mathrm{T}$ & 0.066 & 0.057 & Downstream & $1.21(1.02 \sim 1.43)$ & $\underline{0.031}$ & $0.06 \pm 0.56$ & 0.910 & $0.01 \pm 0.38$ & 0.977 \\
\hline 2 & rs2932966 & $\mathrm{C}$ & 0.075 & 0.088 & Intron & $0.80(0.69 \sim 0.93)$ & $\underline{4.60 \times 10^{-3}}$ & $-1.21 \pm 0.47$ & $\underline{9.74 \times 10^{-3}}$ & $-0.94 \pm 0.32$ & $\underline{2.98 \times 10^{-3}}$ \\
\hline 3 & rs10938963 & $\mathrm{T}$ & 0.438 & 0.427 & Intron & $1.04(0.96 \sim 1.13)$ & 0.354 & $0.22 \pm 0.26$ & 0.397 & $0.27 \pm 0.18$ & 0.125 \\
\hline 4 & rs1472095 & $\mathrm{T}$ & 0.074 & 0.087 & Intron & $0.80(0.68 \sim 0.93)$ & $\underline{3.59 \times 10^{-3}}$ & $-1.30 \pm 0.47$ & $\underline{5.41 \times 10^{-3}}$ & $-0.90 \pm 0.32$ & $\underline{4.60 \times 10^{-3}}$ \\
\hline 5 & rs3774908 & $\mathrm{G}$ & 0.217 & 0.214 & Intron & $1.03(0.93 \sim 1.14)$ & 0.558 & $-0.24 \pm 0.32$ & 0.449 & $-0.29 \pm 0.22$ & 0.178 \\
\hline 6 & rs3774907 & G & 0.223 & 0.216 & Intron & $1.05(0.95 \sim 1.15)$ & 0.367 & $0.58 \pm 0.31$ & 0.061 & $0.41 \pm 0.21$ & 0.053 \\
\hline 7 & rs2290604 & $\mathrm{G}$ & 0.216 & 0.213 & Intron & $1.03(0.93 \sim 1.14)$ & 0.539 & $-0.26 \pm 0.32$ & 0.423 & $-0.29 \pm 0.22$ & 0.188 \\
\hline 8 & rs6448226 & $\mathrm{C}$ & 0.488 & 0.487 & Intron & $1.02(0.94 \sim 1.10)$ & 0.667 & $0.07 \pm 0.26$ & 0.787 & $-0.06 \pm 0.18$ & 0.753 \\
\hline 9 & rs6448227 & A & 0.271 & 0.269 & Intron & $1.00(0.91 \sim 1.10)$ & 0.977 & $0.42 \pm 0.29$ & 0.149 & $0.35 \pm 0.20$ & 0.079 \\
\hline 10 & rs 10007750 & G & 0.206 & 0.206 & Intron & $1.00(0.90 \sim 1.11)$ & 0.979 & $0.56 \pm 0.32$ & 0.084 & $0.38 \pm 0.22$ & 0.081 \\
\hline 11 & rs7656250 & G & 0.391 & 0.403 & Intron & $0.93(0.86 \sim 1.01)$ & 0.100 & $-0.44 \pm 0.27$ & 0.096 & $-0.38 \pm 0.18$ & $\underline{0.035}$ \\
\hline 12 & rs10212638 & G & 0.069 & 0.075 & Intron & $0.93(0.79 \sim 1.09)$ & 0.392 & $0.69 \pm 0.50$ & 0.163 & $0.48 \pm 0.34$ & 0.155 \\
\hline 13 & rs16874265 & A & 0.107 & 0.111 & Intron & $0.96(0.84 \sim 1.10)$ & 0.538 & $0.11 \pm 0.42$ & 0.801 & $-0.07 \pm 0.28$ & 0.810 \\
\hline 14 & rs17576121 & G & 0.026 & 0.021 & Intron & $1.09(0.83 \sim 1.42)$ & 0.553 & $0.74 \pm 0.89$ & 0.409 & $0.73 \pm 0.61$ & 0.227 \\
\hline 15 & rs2946386 & G & 0.391 & 0.389 & Intron & $1.01(0.93 \sim 1.10)$ & 0.812 & $-0.29 \pm 0.27$ & 0.281 & $-0.28 \pm 0.18$ & 0.129 \\
\hline
\end{tabular}

Abbreviations: beta, regression coefficient; CI, confidence interval; MAF, minor allele frequency; OR, odds ratio; se, standard error; SNP, single nucleotide polymorphism; Controls (normotensive), $\mathrm{SBP}<120 \mathrm{mmHg}$ and $\mathrm{DBP}<80 \mathrm{mmHg}$; Cases (hypertensive), $\mathrm{SBP} \geq 140 \mathrm{mmHg}$ and/or DBP $\geq 90 \mathrm{mmHg}$ and/or antihypertensive medication. Statistically significant values $(P<0.05)$ are indicated in bold and underline.

Table 3. Results of the HaploReg of SNP in the KL gene on chromosome 20

\begin{tabular}{|c|c|c|c|c|c|c|c|}
\hline \multirow{2}{*}{ No. } & \multirow{2}{*}{ SNP } & \multirow{2}{*}{ A1 } & \multirow{2}{*}{$\mathrm{A} 2$} & \multirow{2}{*}{ ASN freq } & \multirow{2}{*}{$\begin{array}{l}\text { Case freq of } \\
\text { this study }\end{array}$} & & \\
\hline & & & & & & Enhancer histone marks & Motifs changed \\
\hline 1 & rs2932966 & $\mathrm{C}$ & A & 0.06 & 0.075 & HRT & 10 altered motifs \\
\hline 2 & rs1472095 & $\mathrm{T}$ & $\mathrm{C}$ & 0.06 & 0.074 & 4 tissues & 8 altered motifs \\
\hline
\end{tabular}

Abbreviations: SNP, single nucleotide polymorphism; A1, minor allele; A2, major allele; +, affect; HaploReg is a tool for exploring annotations of candidate regulatory SNPs (https://pubs.broadinstitute.org/mammals/haploreg/haploreg_v4.php) 
A

rs2932966

chr4:23806976 C/A

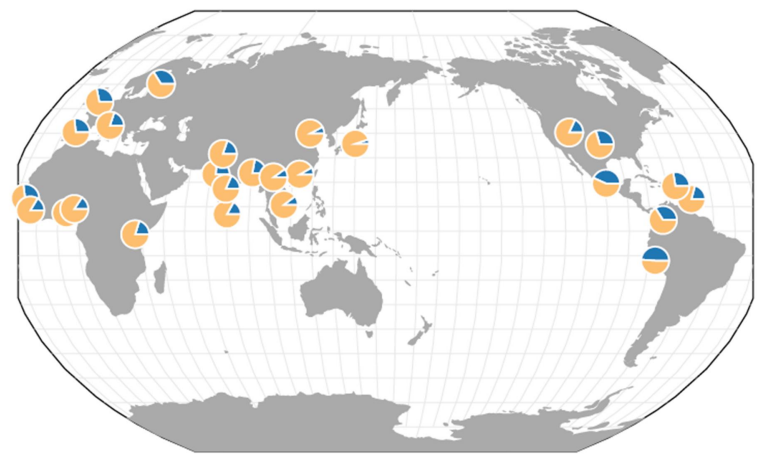

B

rs1472095

chr4:23818077 T/C

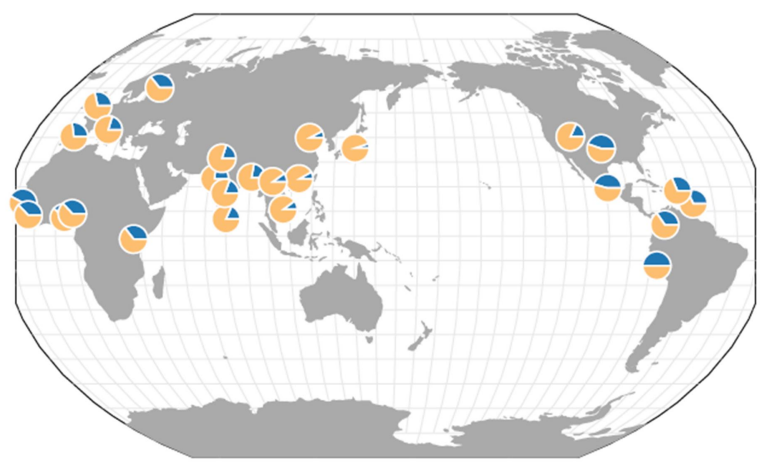

Fig. 1. The worldwide geographic distribution of genetic polymorphisms using 1000 Genomes Project Consortium data. A. Geographic distribution of genetic variant of PPARGC1A rs2932966 are distributed on maps of minor (C) allele frequencies in populations. B. Similarly, genetic polymorphism of PPARGC1A rs1472095 are distributed on maps of minor (T) allele frequency in populations over the globe. The blue slices of the pie chart show a minor allele frequency of each regional population globally.

분석과 SBP, DBP 모두에서 유의성이 있었던 2개의 SNP 들은 enhancer histone marks와 motifs changed에서 SNP의 allele에 따라 차이가 나는 것을 보여주고 있었다. 이는 2개의 SNP의 염기 변화에 따라 유전자 발현 등에 영향을 줄 가능성을 의미하고 있다(Table 3).

\section{고 찰}

한국인 유전체분석자료(KARE)를 기반으로 $P P A R G C 1 A$ 유전자의 영역에 위치한 15 개의 SNP 유전변이들을 대상 으로 고혈압(hypertension) 및 중간 표현형인 수축기 혈압 (systolic blood pressure, SBP)과 이완기 혈압(diastolic blood pressure, DBP) 등과의 상관관계를 통계 분석하여 확인하 였다. 이 중 3개의 SNP들(rs9790699, rs2932966, rs1472095) 이 통계적인 유의성 $(P<0.05)$ 을 나타내었다. 이 중 rs1472095 가 고혈압과 통계적으로 가장 유의한 값을 보였 다( $P$-value, 0.00359$)$.

다량의 exome과 whole genome sequencing 프로젝트를 데이터베이스에서 얻은 GnomAD (The Genome Aggregation Database)-한국인 1,909명 포함된 Whole Exome Sequencing에서는 rs2932966은 minor allele $(\mathrm{C})$ 를 지닐 경우 $\mathrm{C}=0.2659$, major allele $(\mathrm{A})$ 를 지닐 경우는 $\mathrm{A}=0.7341$ 이었다. 특히, 베트 남인의 경우 $\mathrm{C}=0.1121, \mathrm{~A}=0.8879$ 로 나타나 상대적으로 낮 은 minor allele $(\mathrm{C})$ 를 지니고 있었다. 반면에, rs1472095는 GnomAD에서는 minor allele $(\mathrm{T})$ 를 지닐 경우, $\mathrm{T}=0.3097$, major allele $(\mathrm{C})$ 를 지닐 경우는 $\mathrm{C}=0.6903$ 이었다. 본 연구 에서 분석한 minor allele의 경우 $\mathrm{rs} 2932966$ (C)는 0.075 를 rs1472095 (T)는 T=0.074를 나타내어 유럽인이 대다수를 차지하는 $\mathrm{GnomAD}$ 에서의 minor allele 빈도수보다 한국 인이 상대적으로 더 낮은 빈도수(minor allele frequency) 를 갖는 다는 점을 알게 되었다(Fig. 1, Table 3). 한편, 1000 Genome Project를 기반으로 한 GGV browser와 HaploReg 분석프로그램을 이용하여 인트론에 위치한 PPARGCIA 유전변이 rs2932966의 minor allele은 지역마다 조금씩 다 른 양상을 나타내었다. 아프리카인(C)은 $\mathrm{C}=0.22$, 아메리 카인 $(\mathrm{C})$ 은 $\mathrm{C}=0.38$, 유럽인 $(\mathrm{C}) \mathrm{C}=0.25$, 아시아인은 $\mathrm{C}=0.06$ 을 보였다. 아시아인들 중 동아시아인 $(\mathrm{C})$ 은 $\mathrm{C}=0.08$ 이었고 남아시아인(C)은 $\mathrm{C}=0.2$ 를 나타내 주어 동양인들 사이에 도 지역에 따라 유전변이 염기 빈도가 큰 차이를 있음을 확인하였고 본 연구의 Case 빈도(C)를 보면 0.075 를 나타 내어 동아시아인들과 유사한 minor allele frequency를 나 타내었다. 동아시아인의 구성은 주로 한족 중국인과 일 본인 그리고 베트남인으로 구성되어 있다. 비슷한 방법으 로 PPARGC1A rs1472095의 minor allele은 아프리카인(T) 은 $\mathrm{T}=0.39$, 아메리카인( $\mathrm{T})$ 은 $\mathrm{T}=0.40$, 유럽인( $\mathrm{T})$ 은 $\mathrm{T}=0.25$, 아시아인(T)은 $\mathrm{T}=0.06$ 을 보였다. 동아시아인( $\mathrm{T})$ 은 $\mathrm{T}=0.08$, 남아시아인(T)은 $\mathrm{T}=0.21$ 을 보였다. 본 연구의 Case 빈도 (T)는 0.074를 보여주어서 rs2932966처럼 rs1472095도 동 아시아인들과 유사한 minor allele frequency를 나타내었다. 동아시아인 구성은 중국 한족인(T) $\mathrm{T}=0.09$, 베트남인(T) 
$\mathrm{T}=0.2$ 그리고 일본인은 $\mathrm{T}=0.05$ 를 나타내어 한국인과 일본 인에서 상대적으로 낮은 $(\mathrm{T})$ 염기 빈도수를 나타내었다. 2008년 Ingelsson 등은 PPARGC1A Gly482Ser 코딩 SNP 가 남성의 좌심실 이완 기능장애와 연관성이 있음을 보고 하였다. 같은 해 Vimaleswaran 등은 PPARGC1A Gly482Ser (rs8192678) missense 돌연변이가 혈압을 조절한다는 보고 가 있다. 이들 연구에 사용된 코호트는 유럽, 아시아, 아 메리칸 인디언 성인들과 남아메리카 청소년을 대상으로 하였으며 50세 이하의 성인과 연관성이 있음을 나타내었 다. 본 연구는 $\mathrm{KARE}$ 데이터를 기반으로 $P P A R G C 1 A$ 의 유전변이가 고혈압(hypertension) 및 중간 표현형인 $\mathrm{SBP}$ 와 $\mathrm{DBP}$ 와의 연관성 연구(case-control study)을 진행하였다. 그 결과, 기존에 혈압에 대해서는 보고되지 않았던 2 개의 유 전변이가 혈압 수치를 낮추고 고혈압에 대한 위험성을 높이는 경향으로의 상관관계가 있음을 한국인을 대상으로 하여 밝혔다. 이러한 결과는 비록 유전자 수준에서의 고 혈압과의 상관관계는 존재하고 있었으나, 인종별로 차이 를 보이는 세부적인 유전변이들에 대해서는 인종 특이적 혹은 지역 특이적인 현상을 밝혀 내기 위한 연구가 필요 하다는 것을 보여주고 있다

\section{ACKNOWLEDGEMENT}

This study was supported by Basic Science Research Program through the National Research Foundation of Korea (NRF) grant (http://nrf.re.kr) to H.S.J (NRF-2017R1D1A3B03034752), and to S.P. (NRF-2017R1D1A3B03029902). Epidemiologic data used in this study were from the Korean Genome and Epidemiology Study (KoGES) of the Korea Centers for Disease Control \& Prevention, Republic of Korea.

\section{CONFLICT OF INTEREST}

The authors declare that they have no conflict of interest.

\section{REFERENCES}

Ahmetov II, Fedotovskaya ON. Current Progress in Sports Genomics. Adv Clin Chem. 2015. 70: 247-314.

Cabrera CP, Ng FL, Nicholls HL, Gupta A, Barnes MR, Munroe $\mathrm{PB}$, et al. Over 1000 genetic loci influencing blood pressure with multiple systems and tissues implicated. Hum Mol Genet. 2019. 21; 28: R151-R161.

Carretero OA, Oparil S. Essential hypertension. Part I: definition and etiology. Circulation. 2000. 101: 329-335.

Cho YS, Go MJ, Kim YJ, Heo JY, Oh JH, Ban HJ, et al. A largescale genome-wide association study of Asian populations uncovers genetic factors influencing eight quantitative traits. Nat Genet. 2009. 41: 527-534.

El Rouby N, McDonough CW, Gong Y, McClure LA, Mitchell $\mathrm{BD}$, Horenstein RB, et al. Genome-wide association analysis of common genetic variants of resistant hypertension. Pharmacogenomics J. 2019. 19: 295-304.

Healthcare Bigdata, and Health Insurance Review \& Assessment Service, 2019 http://opendata.hira.or.kr/op/opc/olapMfrnIntrs IlnsInfo.do

Ingelsson E, Bennet L, Ridderstråle M, Söderström M, Råstam L, Lindblad U. The PPARGC1A Gly482Ser polymorphism is associated with left ventricular diastolic dysfunction in men. BMC Cardiovasc Disord. 2008. 8: 37.

Kearney PM, Whelton M, Reynolds K, Muntner P, Whelton PK, He J. Global burden of hypertension: analysis of worldwide data. Lancet. 2005. 365: 217-223.

Li TT, Tan TB, Hou HQ, Zhao XY. Changes in peroxisome proliferatoractivated receptor alpha target gene expression in peripheral blood mononuclear cells associated with non-alcoholic fatty liver disease. Lipids Health Dis. 2018.17: 256.

Marcus JH, Novembre J. Visualizing the geography of genetic variants. Bioinformatics. 2017. 33: 594-595.

Martinez-Redondo V, Pettersson AT, Ruas JL. The hitchhiker's guide to PGC-1alpha isoform structure and biological functions. Diabetologia. 2015. 58: 1969-1977.

Pan S, Naruse H, Nakayama T. Progress and issues of the genomewide association study for hypertension. Curr Med Chem. 2015. 22: 1016-1029.

Petr M, Maciejewska-Skrendo A, Zajac A, Chycki J, Stastny P. Association of Elite Sports Status with Gene Variants of Peroxisome Proliferator Activated Receptors and Their Transcriptional Coactivator. Int J Mol Sci. 2019. 21: 162.

Popov DV. Adaptation of Skeletal Muscles to Contractile Activity of Varying Duration and Intensity: The Role of PGC- $1 \alpha$. Biochemistry (Mosc). 2018. 83: 613-628.

Puigserver P, Wu Z, Park CW, Graves R, Wright M, Spiegelman BM. A cold-inducible coactivator of nuclear receptors linked to adaptive thermogenesis. Cell. 1998. 92: 829-839.

Qiu L, Fan X, Zhang Y, Teng X, Miao Y. Molecular characterization, tissue expression and polymorphisms of buffalo PPARGC1A gene. Arch Anim Breed. 2020. 63: 249-259. 
Singh M, Singh AK, Pandey P, Chandra S, Singh KA, Gambhir IS. Molecular genetics of essential hypertension. Clinical and Experimental Hypertension. 2016. 38: 268-277.

Sinha RA, Rajak S, Singh BK, Yen PM. Hepatic Lipid Catabolism via PPAR $\alpha$-Lysosomal Crosstalk. Int J Mol Sci. 2020. 21: 2391.

Vargas-Sánchez K, Vargas L, Urrutia Y, Beltrán I, Rossi AB, Lozano HY, et al. PPAR $\alpha$ and PPAR $\beta / \delta$ are negatively correlated with proinflammatory markers in leukocytes of an obese pediatric population. J Inflamm (Lond). 2020. 17: 35.

Vimaleswaran KS, Luan J, Andersen G, Muller YL, Wheeler E, Brito EC, et al. The Gly482Ser genotype at the PPARGC1A gene and elevated blood pressure: a meta-analysis involving 13,949 individuals. J Appl Physiol (1985). 2008. 105:13521358.

Warren HR, Evangelou E, Cabrera CP, Gao H, Ren M, Mifsud B, et al. Genome-wide association analysis identifies novel blood pressure loci and offers biological insights into cardiovascular risk. Nat Genet. 2017. 49: 403-415.

World Health Organization. A Global Brief on Hypertension: Silent Killer, Global Public Health Crisis. Geneva, Switzerland: World Health Organization, 2013.

Yeligar SM, Kang BY, Bijli KM, Kleinhenz JM, Murphy TC, Torres G, et al. PPAR $\gamma$ Regulates Mitochondrial Structure and Function and Human Pulmonary Artery Smooth Muscle Cell Proliferation. Am J Respir Cell Mol Biol. 2018. 58: 648657.

https://doi.org/10.15616/BSL.2021.27.1.12

Cite this article as: Jin HS, Park S. Association of PPARGC1A Gene Variants with Hypertension in Korean Population. Biomedical Science Letters. 2021. 27: 12-18. 